\title{
MODELING AND SIMULATION OF A SUPERVISION AND MANAGEMENT SYSTEM OF HYBRID ENERGY SYSTEMS FOR THE PANTANAL REGION
}

\author{
Daniela Luiza Catelan Carneiro, João Onofre Pereira Pinto, Ruben Barros Godoy, Alexandra Maria A. C. Pinto \\ Department of Electrical Engineering \\ DEL., Federal University of Mato Grosso do Sul \\ BATLAB - Laboratory of Artificial Intelligence, Digital Systems and Power Electronics \\ Campus of Campo Grande - MS, \\ Phone/Fax number: +5567 33457473 / 556733457543 \\ e-mail: daniela@batlab.ufms.br, jpinto@nin.ufms.br, ruben@batlab.ufms.br, alexandra@batlab.ufms.br
}

\begin{abstract}
This work developed a modeling for simulation of a supervising and management system for hybrid energy systems. The modeling uses many renewable energy sources and a battery bank. The developing was done using MATLAB/SIMULINK ${ }^{\circledR}$. The main objective is to attend the demand of the Pantanal Study Base (BEP) of the Federal University of Mato Grosso do Sul only with renewable energy sources. So, scenarios of typical days and a one year scenario were developed to verify the behavior of the battery bank. It is possible verify how dimensioning of the number of solar panels and of the battery bank can influence the project development, increasing the number of equipments and financial costs. First, hybrid energy systems and renewable energy sources are briefly presented. Then the model is described. Following, how the demand curve was obtained is presented, and the dimensioning of the number of solar panels and the number of batteries of the battery bank. Finally, results obtained with the modeling of the system are presented.
\end{abstract}

\section{Keywords}

Hybrid energy systems, renewable energy sources and demand curve.

\section{Introduction}

In Brazil, electrical energy is mainly distributed through transmission lines, which is difficult in distant regions.

Renewable energy sources such as solar voltaic, eolic, biomass and small hydroelectric plants are among the best options for places where transmission lines are not viable.

Renewable energy sources can be used in conjunction, constituting a hybrid power generation system. Because it uses more than one primary energy source, hybrid systems are the ideal way to produce electrical energy for isolated communities.

In this work, three renewable energy sources were used: solar, biomass and biogas.
Solar irradiation data were obtained from CPTEC (Weather Prediction and Climate Studies Center) [1], in Corumbá - MS, where the BEP is located.

Knowing that one person produce around $0.6 \mathrm{~kg}$ of waste per day [2], it was possible to obtain the amount of biomass.

Also, it is estimated that one person produce around 0.3 $\mathrm{m}^{3}$ of wastewater per day, which correctly converted can produce $0.02 \mathrm{~m}^{3}$ of biogas [3].

\section{Management Model}

It was developed a modeling for the simulation of a supervision and management system for hybrid energy systems. This system was developed using Matlab ${ }^{\circledR}$, trough Simulink ${ }^{\circledR}$. Modeling developing is shown on Figure 1.

The developed system verifies if the amount of biogas, biomass and solar energy is enough, and if there is excess energy to accumulate into the Battery Bank (BB).

If the quantity of biogas is not enough, the amount of biomass is verified. If there is some surplus, it can be used to attend the next demand. It was chosen to use biogas and biomass first in order to load the bioreactor during the next day.

Solar energy is used when the amount of biogas and biomass can not attend demand. Solar energy surplus is goes to the BB. Not having solar energy to attend the load, BB is activated.

The developed battery bank is activated only when renewable energy is not enough to attend the load. 


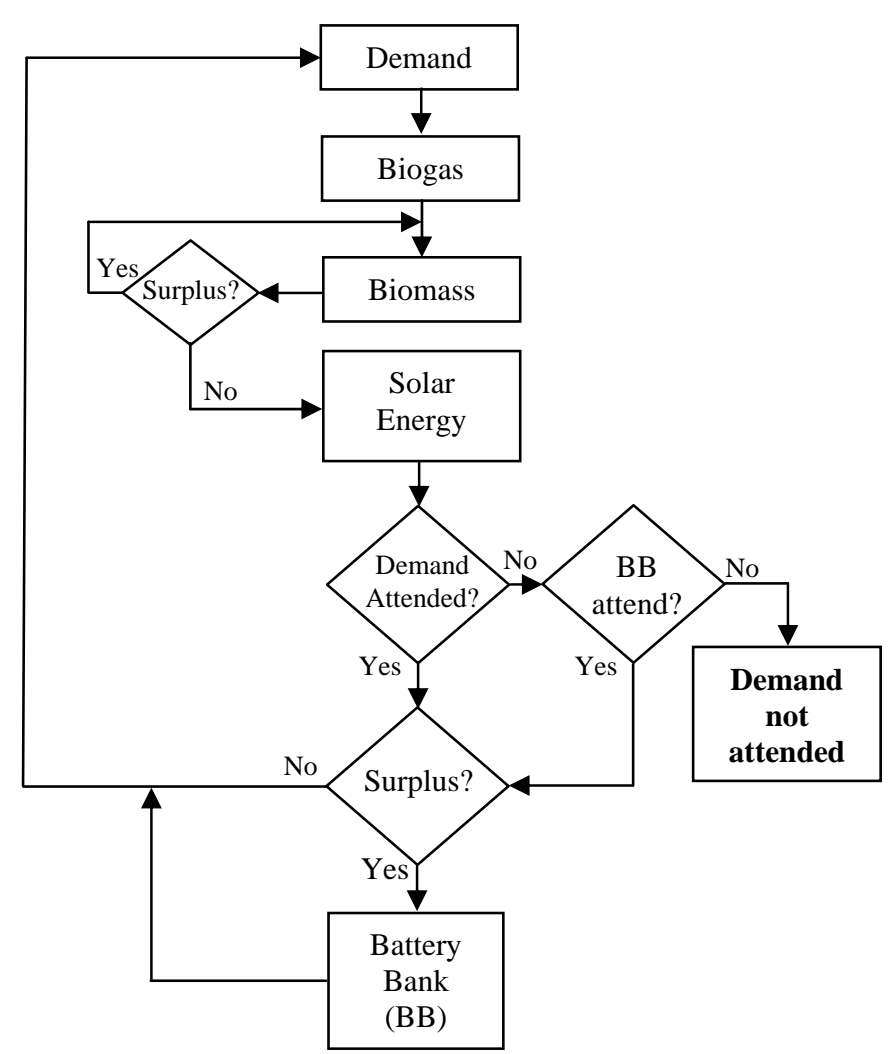

Fig. 1 - Fluxogram of the modeling used for the simulation of the supervision and management system.

\section{Modeling}

The BEP was chosen to develop this work because it is located at the Passo do Lontra region, $300 \mathrm{~km}$ from Campo Grande, state capital. Even being located on the Pantanal region, BEP does not use any source of renewable energy; it only uses energy provided by the concessionary.

\section{A. Demand Curve}

Wind velocity, temperature and solar radiation data were collected from CPTEC. Biomass and biogas data were calculated based on the number of BEP's guests per day.
Due to the great amount of obtained data, a solution was to separate them on seasons. Table 1 shows the average of the collected data by seasons.

The demand curve was obtained based on methodologies developed by [4].

In [4] the author submitted a demand curves data bank to an artificial neural network to find resemblance patterns and separate them into groups. Approximation was used to identify consumer's typical demand curves based on the attributes of the databank.

The author [4] presented four methodologies to obtain typical demand curves: consumption extract and consumer type, consumption extract and grouped consumer type, Fuzzy Method and grouping analysis.

Based on this, BEP's typical demand curve, for the day with more guests is shown of Figure 2.

\section{B. Solar Panel Dimensioning}

To dimension de number of solar panels the peak demand method was used, in this case $30 \mathrm{~kW}$. It was obtained 357 panels, with $43.2 \mathrm{~kW}$ and area of $332 \mathrm{~m}^{2}$. However, based on many tests it was observed that using 230 panels of $130 \mathrm{Wp}$, with area of $214 \mathrm{~m}^{2}$ and $27.8 \mathrm{~kW}$ all possible canaries can be attended, including surplus on the Battery Bank.

\section{Battery Bank Dimensioning}

The use of the Battery Bank is more common in small and medium hybrid energy systems, and it is used to save fossil fuels. BB supplies energy when the amount of renewable energy is not enough [5].

In this work, BB design was made for maximum (65), medium (27) and minimum (2) number of BEP's guests.

TABLE 1: Average of the data collected for the seasons.

\begin{tabular}{|c|c|c|c|c|c|c|c|c|c|c|c|c|}
\hline & \multicolumn{3}{|c|}{ Fall } & \multicolumn{3}{|c|}{ Winter } & \multicolumn{3}{|c|}{ Spring } & \multicolumn{3}{|c|}{ Summer } \\
\hline & \begin{tabular}{|c|}
$21 / 3$ \\
- \\
$21 / 4$
\end{tabular} & $\begin{array}{c}22 / 4 \\
- \\
21 / 5\end{array}$ & $\begin{array}{c}22 / 5 \\
- \\
21 / 6\end{array}$ & $\begin{array}{c}22 / 6 \\
- \\
21 / 7\end{array}$ & $\begin{array}{c}22 / 7 \\
- \\
21 / 8\end{array}$ & $\begin{array}{c}22 / 8 \\
- \\
23 / 9\end{array}$ & $\begin{array}{c}24 / 9 \\
- \\
25 / 10\end{array}$ & $\begin{array}{c}26 / 10 \\
- \\
26 / 11\end{array}$ & $\begin{array}{c}27 / 11 \\
- \\
21 / 12\end{array}$ & $\begin{array}{c}22 / 12 \\
- \\
22 / 1\end{array}$ & $\begin{array}{c}23 / 1 \\
- \\
23 / 2\end{array}$ & $\begin{array}{c}24 / 2 \\
- \\
20 / 3\end{array}$ \\
\hline Guests (person) & 13 & 23 & 27 & 37 & 24 & 26 & 13 & 18 & 11 & 8 & 16 & 3 \\
\hline Temp. $\left(\mathrm{C}^{\circ}\right)$ & 26,5 & 23,0 & 20,2 & 20,2 & 20,2 & 25,2 & 26,0 & 26,5 & 26,4 & 27,0 & 26,7 & 26,5 \\
\hline Wind velocity $(\mathrm{m} / \mathrm{s})$ & 2,7 & 3,6 & 3,5 & 3,8 & 4,6 & 4,3 & 3,9 & 3,4 & 3,1 & 3,5 & 3,1 & 2,8 \\
\hline Solar radiation $\left(\mathrm{MJ} / \mathrm{m}^{2}\right)$ & 2,6 & 2,2 & 2,0 & 1,9 & 2,4 & 1,9 & 2,2 & 2,6 & 1,9 & 2,3 & 2,2 & 2,6 \\
\hline Biomass (MJ) & 47,3 & 76,1 & 87,1 & 120,1 & 78,4 & 84,3 & 43,1 & 60,3 & 37,6 & 27,1 & 53,3 & 10,5 \\
\hline Biogas $\left(\mathrm{MJ} / \mathrm{m}^{3}\right)$ & 6,6 & 11,7 & 13,4 & 18,5 & 12,1 & 13,0 & 6,6 & 9,3 & 5,6 & 4,0 & 8,2 & 1,6 \\
\hline
\end{tabular}




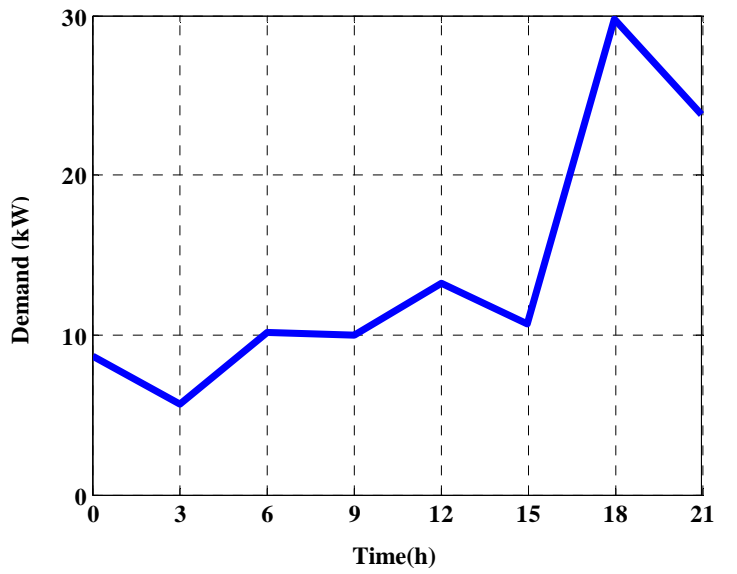

Fig. 2. Typical Demand Curve

Equation (1) was used determine BB's capacity with load enough for one day, where daily consumption is divided by bank voltage. To find the number of batteries it is necessary to choose a load factor and the battery Ah quantity. (2)

$$
\begin{gathered}
\text { CapBB }=\frac{\text { daily_consumption }(\mathrm{kWh})}{12 \mathrm{~V}} \\
B=\frac{\mathrm{CapBB}}{0,8 * 150 \mathrm{Ah}}
\end{gathered}
$$

Daily consumption was defined by the sum of generated power (biomass, biogas and solar energy) subtracted from the demanded power.

Daily consumptions are 95,700.00 Wh, 254,400.00 Wh and $329,100.00$ Wh. The number of batteries for the maximum number of guests are 67, 177 batteries are needed for the medium number of guests, and for the minimum, 229 batteries.

It was verified that 67 batteries are enough to attend most of the loads during the period of one year. In just one moment neither renewable energy sources nor $\mathrm{BB}$ is enough to attend demand, so the concessionary energy can be used or a small diesel generator can be used.

\section{Developing the Scenarios}

For each season a typical day scenario was developed. Maximum and medium visitants number occurs during winter, so for this season two scenarios were developed. One year scenario was developed to analyze the behavior of the demand curve and the battery bank.

\section{A. Scenario 1 - 65 Guests}

This scenario shows data from the day with more guests. Biomass production was $212.4 \mathrm{MJ}$ and biogas produced 32.7 MJ. Solar radiation did not presented elevated values as observed by the dotted line (Figure 3), because this scenario is for winter.

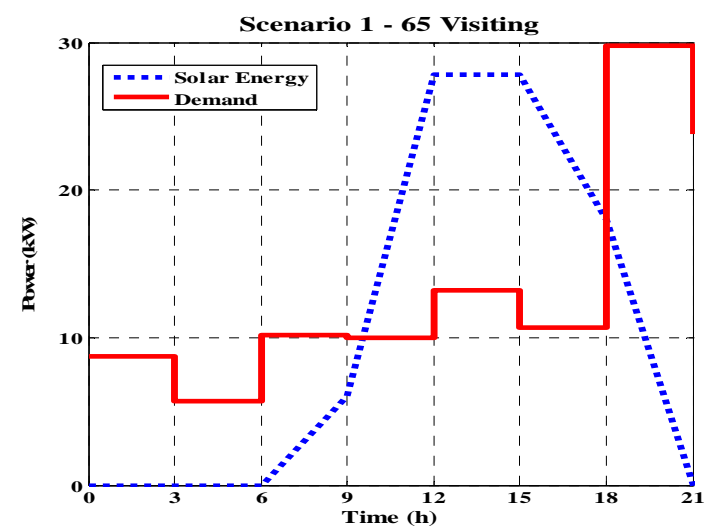

Figure 3: Scenario 1 - 65 Guests

\section{B. Scenario 2 - 40 Guests}

For this scenario biogas production was $130.7 \mathrm{MJ}$ and biogas was 20.1 MJ. During spring, days are longer and solar radiation present higher values (Figure 4).

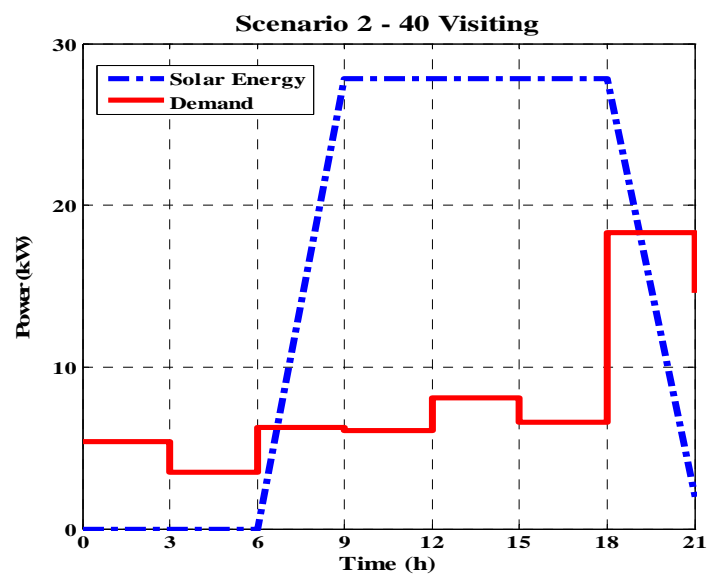

Fig. 4: Scenario $2-40$ Guests

\section{Scenario 3 - 02 Guests}

There were many periods where the BEP did not present any guests. These periods were just considered for the annual scenario analysis. So, two guests were considered as the minimum number for biomass and biogas analysis, 6.5 MJ and 1.0 MJ, respectively. This scenario was found for summer and presents considered values for solar radiation (Figure 5).

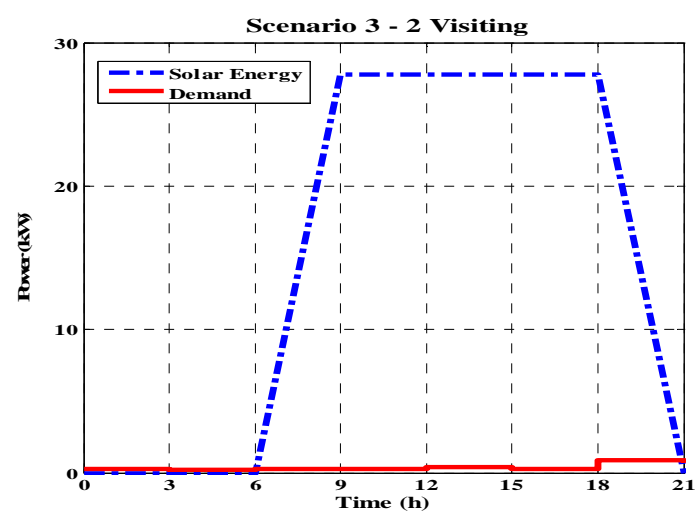

Fig. 5: Scenario 3-02 Guests 


\section{Scenario $4-51$ Guests}

This scenario is for fall, where there is more guests to the BEP. Biomass and biogas production was elevated, 166.6 MJ and 25.6 respectively. During this period there is a small decrease in solar radiation (Figure 6).

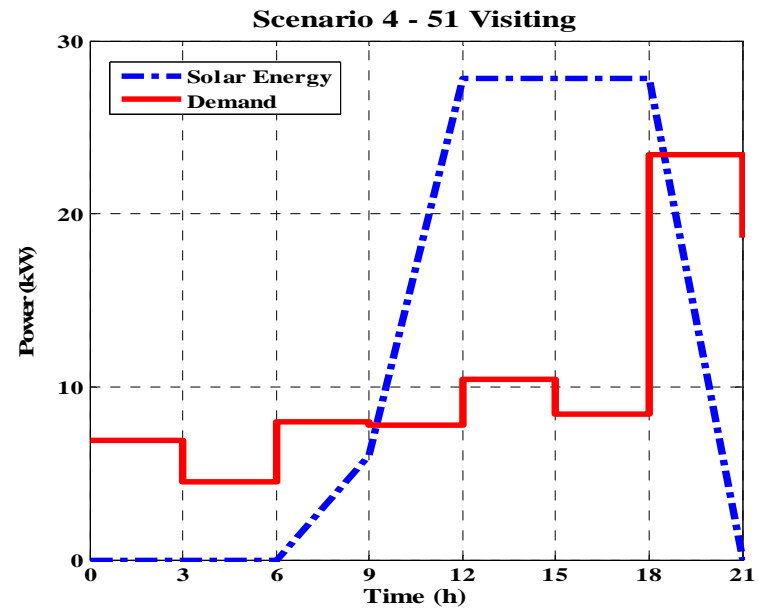

Fig.6: Scenario 4-51 Guests

\section{E. Scenario 5-27 Guests}

This scenario represents medium number of guests and is during winter. It is expected that during winter solar radiation is lower, but high values were obtained. Biomass production was 88.2 MJ and biogas was 13.5 MJ (Figure 7).

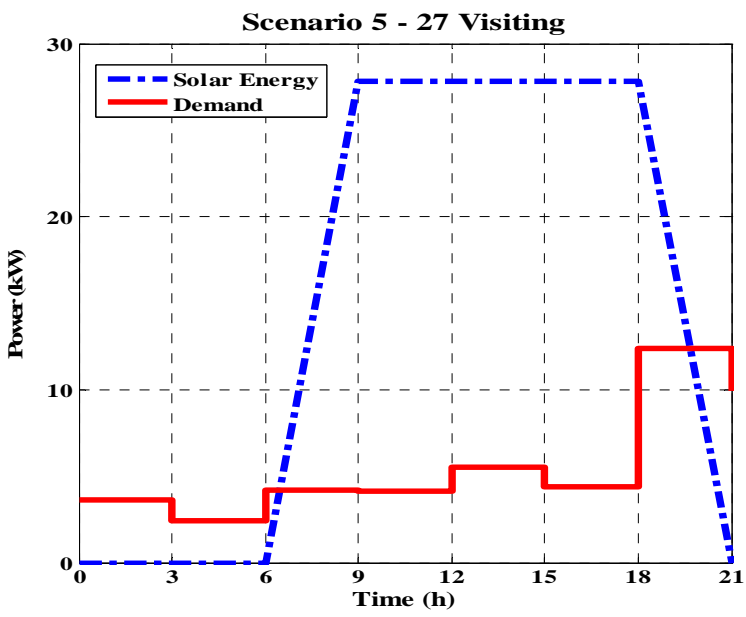

Fig.7: Scenario 5 - 27 Guests

\section{F. One Year Scenario}

This scenario was developed to analyze demand curve and battery bank behavior. Demand curve can be observed on Figure 8. For one year, BEP had 6890 guests, biomass producing 22,517.9 MJ and biogas 1,464.3 MJ.

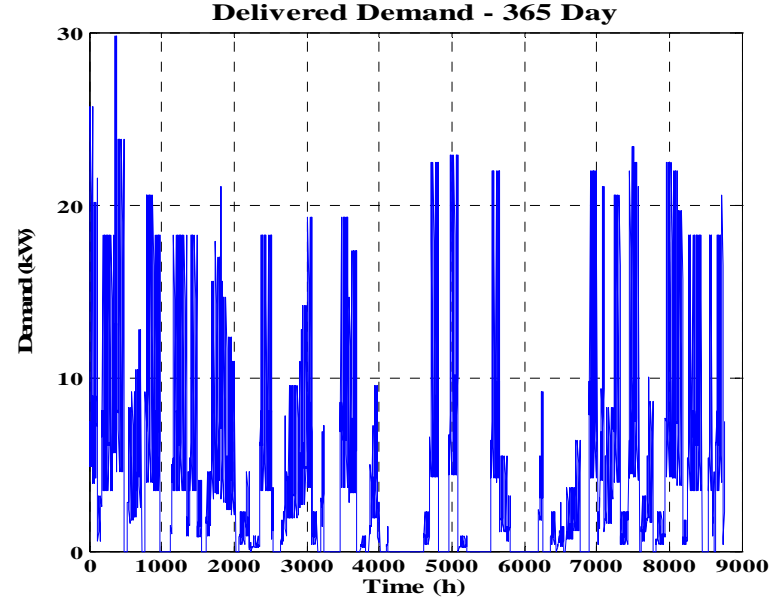

Fig. 8: One Year Scenario.

\section{Results}

Obtained results were satisfactory. All demands were attended and the battery bank did not completely discharged any time. For some scenarios, solar energy surplus were bigger than BB's capacity.

\section{A. Scenario 1}

Biomass and biogas quantities were enough to attend the two demands. The BB was activated and for three times there were overload, but the BB could not be completely recharged. All demands were attended. Figure 9 presents the attended demand and BB's load during 24 hours.
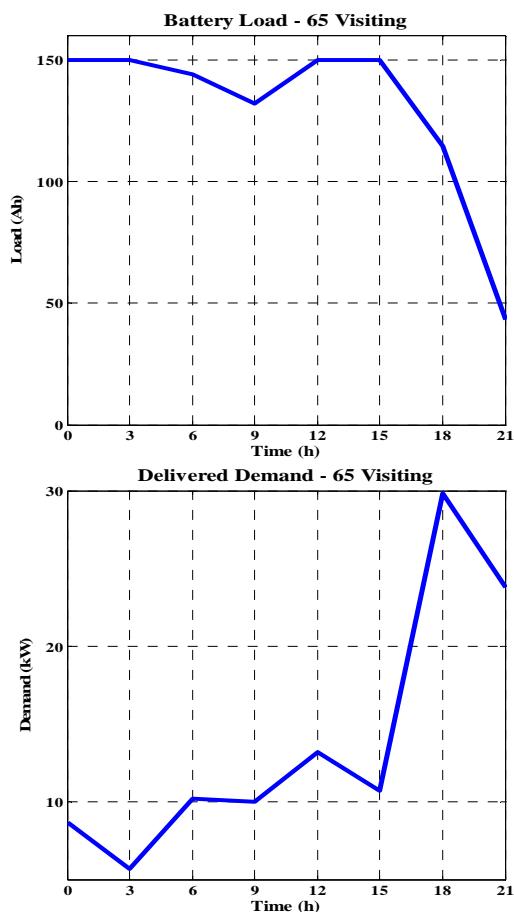

Fig. 9: Load of the Battery Bank and Attended Demands.

\section{B. Scenario 2}

For this scenario there was a big overload on the battery, due to the amount of solar energy, because during spring the days are longer. The final load on the BB was of 
112.20 kWh. Biogas and biomass together attended both demands. All demands were attended (Figura 10).

\section{Scenario 3}

For this scenario, BB's overload almost reached 500 $\mathrm{kWh}$. The motive was the demand, because the number of guests was very small; also, solar energy reached high values because this scenario occurred during summer. Even with low biomass and biogas production, the quantity was enough to attend three demands (Figure 11).
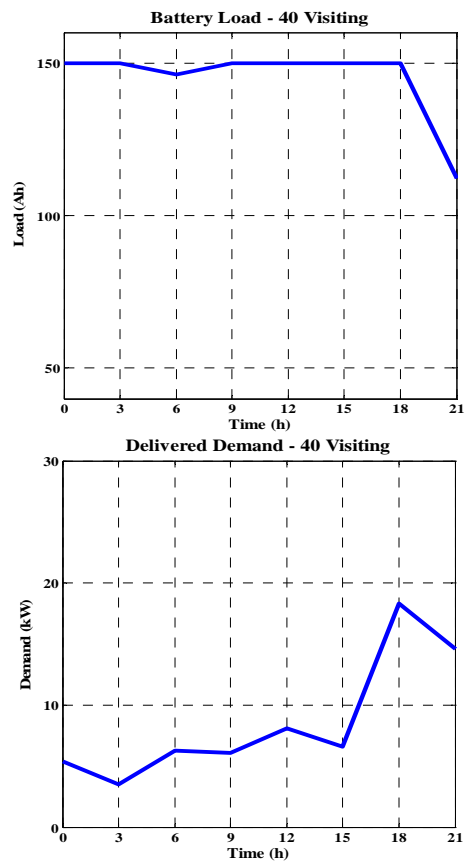

Fig. 10: BB Load and Attended Demands.
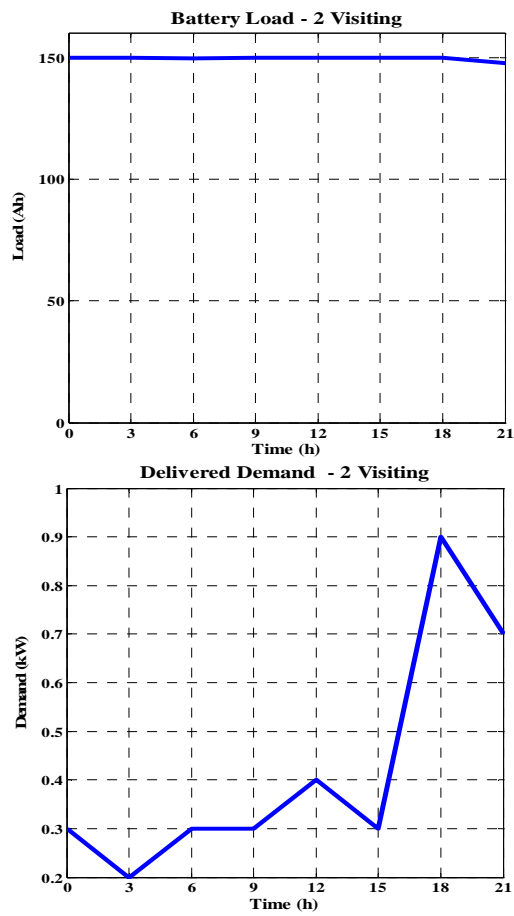

Fig. 11: BB Load and Attended Demands.

\section{Scenario 4}

Because it was fall, solar energy showed some reduction. All demand were attended, however the BB was not tottaly recharged, staying with $94.2 \mathrm{kWh}$ (Figure 12).
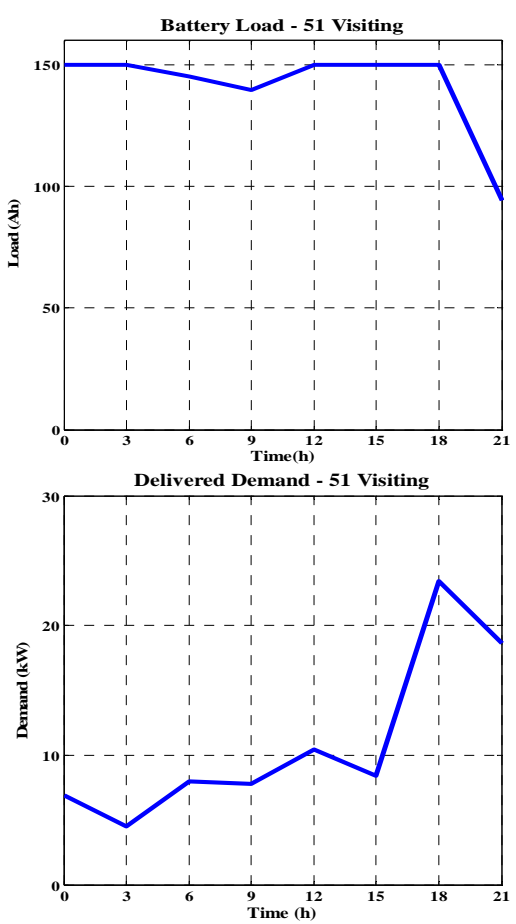

Fig. 12: BB Load and Attended Demands.

\section{E. Scenario 5}

Even being in winter this scenario showed an overload of $402 \mathrm{kWh}$. All demands were attended and the BB had a final load of $120.3 \mathrm{kWh}$ (Figure 13).
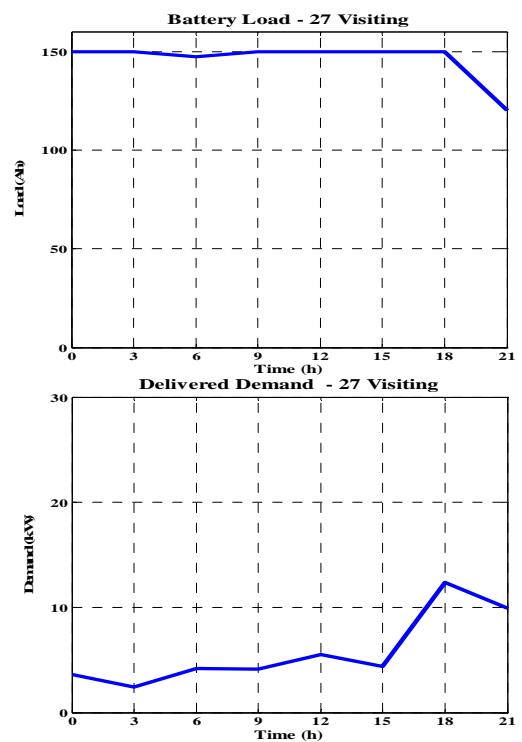

Fig. 13: BB Load and Attended Demands. 


\section{G. One Year Scenario}

During this scenario there was one moment when the BB was completely discharged and could not attend the load. However it occurred just one time and all the other demands were attended, so there is no need to increase the BB. When it occur a diesel generator or energy from de concessionary can be used. The occurrence of zero demands does not indicate that the demand was attended; it may be that there were no guests in the BEP. Figure 14 represents results obtained for this scenario.
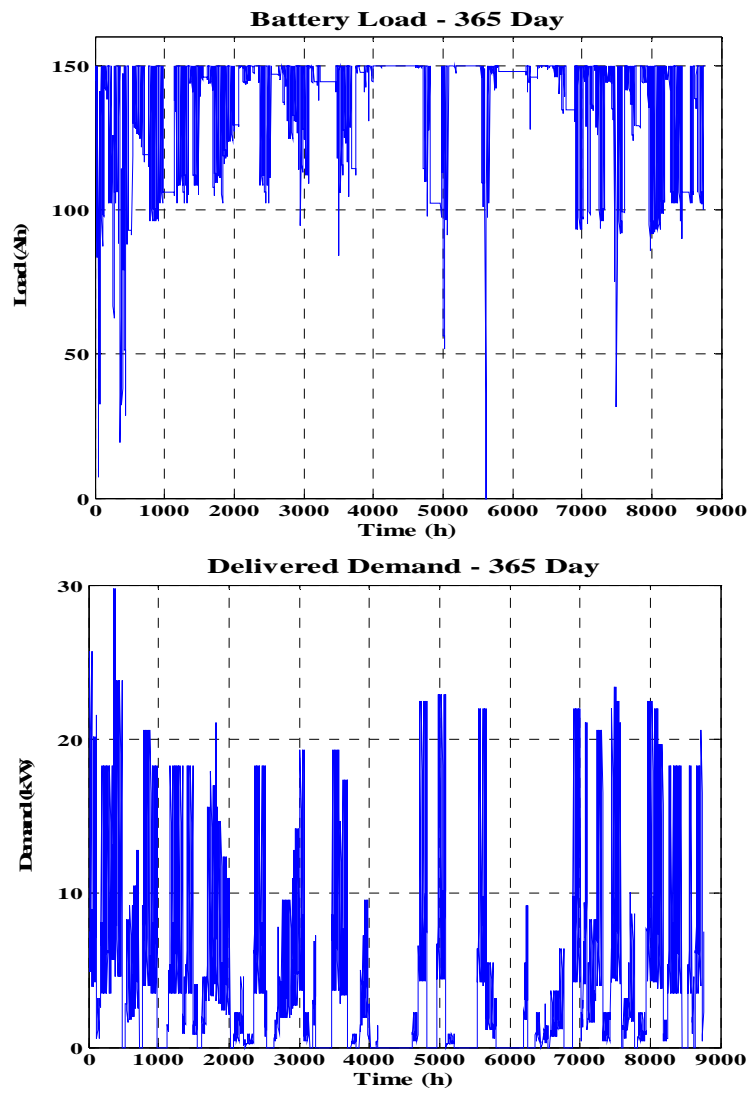

Fig. 14: BB Load and Attended Demands.

\section{Conclusion}

This paper presented the development of a modeling for a supervising and management system for hybrid power energy sources. With the aim of attending the load of the Pantanal Study Base (BEP) of the Federal University of Mato Grosso do Sul this work used renewable energy sources and a battery bank.

The right dimensioning of numbers of solar panels is essential to no dispend energy, and not spend excess money buying unneeded equipments. Using the dimensioning method of peak demand, the number of solar panels would be 357. Analyzing the results obtained with the modeling of this number, the number of panels was reduced to 230 . With this quantity the load is attended and the surplus energy is used to charge the battery bank.
For this work, three battery banks were dimensioned based on the maximum, medium and minimum number of guests of the BEP. It was verified that 84 batteries, a bank of $150 \mathrm{kWh}$ is enough to attend the demand. There is just one instant where the renewable energy sources and the battery bank is not enough to attend the demand. However it was just a short instant, so the best solution is to use a diesel generator or the concessionary energy.

Analyzing the results obtained on the diverse scenarios it is possible to observe that the use of biogas and biomass is very important. They are used when there is not enough solar energy and the demand is small, saving the battery bank for peak time.

Future research focus on the development of an almost optimum supervising and management system of hybrid power systems using a global search algorithm called Algorithm of Differential Evolution. The application will be for remote regions in general; however more attention will be for isolated areas of Pantanal in Mato Grosso do Sul. Control must be done such the system work mainly on renewable energy sources, minimizing the use of fossil fuels.

\section{References}

[1] Weather Prediction and Climate Studies Center. Web Site: www.cptec.com.br. Access : 08/26/2007.

[2] E. Godoy Jr., G. E. O. Giacaglia, J. L. Silveira, J. R. Camargo. "Studies on Technical and Economical Feasibility of Digesters Anaerobic-Aerobic-Anox to Sevage Treatment, Water Reuse and Use of Biogas”. Proceedings of the 20 th International Conference on Efficiency, Cost, Optimization, Simulation and Environmental Impact of Energy Systems. Padova: SG Editoriali, 2007. p. 769-776.

[3] L. C. Lange, G. F. Simões, C. F. Ferreira. "Engineered Landfills for Small Communities - A Case Study for Catas Altas, Minas Gerais, Brazil”. ISWA 2002 Annual Congress, Appropriate Environmental and Solid Waste Management and Technologies for Developing Countries. Istambul: v. 1. p. 723-728.

[4] S. C. Cerchiari, A. Teruya, J. O. P Pinto, G. L. Torres, L. Sauer, E. Zorzate, "Data Mining in Distribution Consumer Database using Rough Sets and Self-Organizing Maps”. IEEE PES Power Systems Conference \& Exhibition, PSCE2006, 2006.

[5] J. M. Bolanos, A. L. Pereira, E. A. Fadigas, F. Adegas, "An Intelligent Supervisory Controller for Wind-Diesel-Battery System”. WWEC2007 - World Wind Energy Conference and Exhibition, 2007, Mar del Plata - Argentina. 